\title{
Neurological Involvement in COVID-19 and Potential Mechanisms: A Review
}

\author{
Ghazal Aghagoli ${ }^{1 *}$ D, Benjamin Gallo Marin ${ }^{1}$, Nicole J. Katchur ${ }^{7}$, Franz Chaves-Sell ${ }^{10,11}$, Wael F. Asaad ${ }^{1,2,3,4,5,6}$ \\ and Sarah A. Murphy ${ }^{8,9}$
}

(C) 2020 Springer Science+Business Media, LLC, part of Springer Nature and Neurocritical Care Society

\begin{abstract}
As the current understanding of COVID-19 continues to evolve, a synthesis of the literature on the neurological impact of this novel virus may help inform clinical management and highlight potentially important avenues of investigation. Additionally, understanding the potential mechanisms of neurologic injury may guide efforts to better detect and ameliorate these complications. In this review, we synthesize a range of clinical observations and initial case series describing potential neurologic manifestations of COVID-19 and place these observations in the context of coronavirus neuro-pathophysiology as it may relate to SARS-CoV-2 infection. Reported nervous system manifestations range from anosmia and ageusia, to cerebral hemorrhage and infarction. While the volume of COVID-19-related case studies continues to grow, previous work examining related viruses suggests potential mechanisms through which the novel coronavirus may impact the CNS and result in neurological complications. Namely, animal studies examining the SARS-CoV have implicated the angiotensin-converting-enzyme-2 receptor as a mediator of coronavirus-related neuronal damage and have shown that SARS-CoV can infect cerebrovascular endothelium and brain parenchyma, the latter predominantly in the medial temporal lobe, resulting in apoptosis and necrosis. Human postmortem brain studies indicate that human coronavirus variants and SARS-CoV can infect neurons and glia, implying SARS-CoV-2 may have similar neurovirulence. Additionally, studies have demonstrated an increase in cytokine serum levels as a result of SARS-CoV infection, consistent with the notion that cytokine overproduction and toxicity may be a relevant potential mechanism of neurologic injury, paralleling a known pathway of pulmonary injury. We also discuss evidence that suggests that SARS-CoV-2 may be a vasculotropic and neurotropic virus. Early reports suggest COVID-19 may be associated with severe neurologic complications, and several plausible mechanisms exist to account for these observations. A heightened awareness of the potential for neurologic involvement and further investigation into the relevant pathophysiology will be necessary to understand and ultimately mitigate SARS-CoV-2-associated neurologic injury.
\end{abstract}

Keywords: Coronavirus, Neurology, Cerebrovascular stroke, Inflammation

\section{Introduction}

The novel 2019 coronavirus disease (COVID-19) caused by Severe Acute Respiratory Syndrome coronavirus 2 (SARS-CoV-2) results in a variety of symptoms including fever, cough, and fatigue [1]. As more is learned, it has become apparent that neurologic involvement in

\footnotetext{
*Correspondence: ghazal_aghagoli@brown.edu

1 Warren Alpert Medical School of Brown University, Providence, RI, USA

Full list of author information is available at the end of the article
}

COVID-19 may be important in some patients. A subset of patients presents with neurologic symptoms such as headache, dizziness, or a cerebrovascular event [2]. Reports have also implicated isolated, sudden onset of anosmia and ageusia as early indicators of SARS-CoV-2 infection, suggesting that early neurological involvement may be relevant [3]. Of great concern are the potential long-term neurologic complications from COVID-19 infection. Here, we synthesize the literature to highlight clinical observations that suggest important associations

\section{望 Springer}


between SARS-CoV-2 infection and the nervous system and discuss potential mechanisms of neural injury. Awareness of the possible neurological manifestations in COVID-19 patients is of utmost importance to assist providers in the recognition, treatment, and management of potentially life-threatening neurologic complications.

\section{Clinical Observations}

While SARS-CoV-2 presents primarily as a respiratory disease, injury to other organ systems, including the nervous system, is well documented [4]. These observations shed light on the broad physiological impact of COVID-19, and awareness of these extrapulmonary features may help inform the overall prognosis in patients affected. The reported neurologic effects of COVID-19 infection are myriad and may include complications related to viral infection, immune response, critical illness, related therapies and recovery. A retrospective study of 214 COVID-19 patients from Wuhan, China, found that $36.4 \%$ of patients had neurologic manifestations of the disease, including symptoms relating to the central nervous system (24.8\%), peripheral nervous system (8.9\%) and skeletal muscle injury (10.7\%). The most common neurologic manifestations were dizziness $(16.8 \%)$ and headache (13.1\%). Severely ill patients were more likely than less severely afflicted patients to exhibit neurologic symptoms ( $45.5 \%$ vs. $30.2 \%$, respectively) including cerebrovascular disease (seen in $5.7 \%$ and $0.8 \%$, respectively), impaired consciousness ( $14.8 \%$ vs. $2.4 \%)$, and skeletal muscle injury (19.3\% vs. $4.8 \%$ [ [4].

A recently published report of 58 patients admitted to two intensive care units in Strasbourg, France, with COVID-19-associated-ARDS found neurological features associated with the illness in $14 \%$ of the patients on admission to the ICU, in $67 \%$ when sedation was lifted, and overall in $84 \%$ when considering all neurological complications through hospital discharge. Neurologic symptoms cataloged in this study included agitation (69\%), confusion (65\%), and corticospinal tract signs (67\%). Notably, 33\% of the patients discharged from the hospital were found to have an executive dysfunction syndrome such as inattention, disorientation or poorly organized movements. MRI was performed in 13 of 64 patients for encephalopathic features. Among these, bilateral frontotemporal hypoperfusion abnormalities were seen in $11 / 11(100 \%)$, acute or subacute stroke in $3 / 13(23 \%)$ and enhancement of leptomeningeal spaces in $8 / 13(62 \%)$. Eight patients underwent electroencephalography. One demonstrated a pattern of diffuse bilateral slowing while others had non-specific findings. CSF samples were obtained from 7 patients; two patients had oligoclonal bands, one had elevated protein and IgG levels and no patients had PCR assays positive for SARS-CoV-2
[5]. In another multi-center, retrospective cohort, 50 of 235 ICU patients were found to have neurologic symptoms (21\%) [6]. Twenty-seven of these underwent MRI, and acute imaging abnormalities were found in $44 \%$ $(12 / 27)$ including, most commonly, cortical fluid-attenuated inversion recovery (FLAIR) signal abnormalities in non-specific distributions affecting the frontal, temporal, parietal, occipital, cingulate or insular cortex, as might be seen with infectious or autoimmune encephalitis, a post-ictal state, hypoxia or hypoglycemia. Subcortical and deep white matter signal changes accompanied these findings $(6 / 10)$, and leptomeningeal enhancement (5/8 patients) was also seen. In addition, one patient presented with a large-vessel AIS and another with CVST. CSF testing demonstrated elevated protein in 6 out of 7 patients tested; all had normal cell counts and 2 had negative PCR assays for SARS-CoV-2 [6].

Though case reports of possible encephalitis associated with COVID-19 are reported [7, 8], we found one isolated report of SARS-CoV-2 being detected in the CSF of symptomatic patients. SARS-CoV-2 RNA was detected in the CSF by RT-PCR, but not the nasal swab, of a 24-year-old man in Japan [9]. This patient had clinical findings of encephalitis, including seizure, headache, stiff neck, elevated CSF pressure, and a WBC count of $12 / \mu \mathrm{L}[9]$. Magnetic resonance imaging (MRI) with diffusion weighted imaging (DWI) demonstrated hyperintensity along the inferior horn of the right lateral ventricle, FLAIR sequences showed hyperintense signal changes in the right mesial temporal lobe with hippocampal atrophy, and T2-weighted imaging revealed paranasal sinusitis [9]. This patient was diagnosed with encephalitis associated with SARS-CoV-2 [9]. In contrast, Doung et al. describe a patient with headache and fever who presented with new seizure in the absence of respiratory symptoms. CSF was not tested for SARS-CoV-2, but additional tests did suggest an aseptic meningitis with an elevated WBC count and lymphocytic predominance. A nasopharyngeal swab confirmed COVID-19 infection [7]. In another case, a patient admitted with COVID-19 developed signs of meningeal irritation and alteration in consciousness. A head CT and lumbar puncture were normal. Bacterial and viral CSF studies were negative including SARS-CoV-2 PCR testing, but the patient was diagnosed with COVID-19-associated meningoencephalitis with the authors postulating transient dissemination of the virus in the CSF with a robust inflammatory response [10].

Interestingly, postmortem examination of a patient infected with SARS-CoV-2, who presented with confusion and mental status changes, detected virus in frontal lobe neurons by electron microscopy despite negative CSF PCR testing. Viral particles were also identified in 
brain capillary endothelial cell and seen actively budding from endothelial cells, both providing the first direct evidence of SARS-CoV-2 in human brain tissue and implicating a potential direct hematogenous route for CNS seeding [11]. This report has been followed by a second, identifying and quantifying SARS-CoV-2 virus in brain tissue samples from 8 of 22 patients (36\%) who died from COVID-19 infection [12], more firmly establishing COVID-19's neurotropic potential.

Another case describes a COVID-19 patient with cough, fever, and altered mental status who was diagnosed with acute necrotizing encephalopathy (ANE) [8]. A non-contrast CT demonstrated symmetric hypoattenuation within the bilateral medial thalami with normal $\mathrm{CT}$ angiogram and venogram. MRI showed characteristic hemorrhagic rim enhancing lesions within the thalami, medial temporal lobes, and subinsular regions [8]. ANE is a rare but well-recognized complication of viral illnesses, particularly in children $[13,14]$ and was reported in adults during the novel influenza A H1N1 pandemic [15]. Although the pathogenesis of ANE is not known, it is hypothesized to be immune-mediated, with more than $90 \%$ of cases preceded by fever and upper respiratory infection. Elevated CSF and serum cytokines have been linked to the disease presentation in both adults and children, and some authors have suggested hypercytokinesis may play a role in driving endothelial damage and blood-brain barrier disruption [16-18]. Whether SARS-CoV-2 may cause acute viral meningitis-encephalitis or viral associated encephalopathy syndromes, as have been associated with other viral illnesses, remains to be elucidated.

Acute demyelinating polyneuropathy associated with SARS-CoV-2 infection has also been described [19]. A case series from Italy reports 5 patients who developed Guillain-Barre Syndrome (GBS) between 5 and 10 days after the onset of typically described COVID-19 symptoms, including fever, cough, anosmia and ageusia [20], a similar time-interval to the development of GBS observed in other viral illnesses. SARS-CoV-2 RT-PCR of the CSF was negative in all 5 of these patients [21]. A case of a patient who developed the typical progressive weakness of the distal lower extremities evolving to quadriplegia approximately 2 weeks after acute COVID-19 infection is reported separately [22], as is a series of two patients who developed Miller Fisher variant and polyneuritis cranialis, respectively, notably in the time-course of acute COVID-19 infection [23]. In China, a 61-year-old otherwise asymptomatic woman presented with acute symmetric weakness and areflexia in the lower extremities. This patient was also diagnosed with GBS; 8 days later she developed typical COVID-19 symptoms and SARS$\mathrm{CoV}-2$ infection was confirmed. At the time of hospital discharge, both respiratory and neurological symptoms had resolved [19]. Because relatively little is yet known about SARS-CoV-2, profound muscle weakness and difficulty weaning off the ventilator are well described, and there is significant clinical overlap between critical illness neuropathy-myopathy and the symptoms of GBS, it may be important to consider this atypical complication of viral infection in critically ill patients.

There is now a well-documented association of anosmia and ageusia with COVID-19. Although olfactory dysfunction can commonly occur with viral illness second to mucosal inflammation, what appears to be unique to COVID-19 may be the development of anosmia and hyposmia in the absence of nasal obstruction or rhinorrhea. A study that included 417 patients with mild-to-moderate COVID-19 infection admitted to 12 European hospitals found that $85.6 \%$ and $88.0 \%$ of patients reported anosmia and ageusia, respectively [3]. The concurrent appearance of both symptoms was statistically significant $(p<0.001)$, though either anosmia or ageusia can also occur alone. Olfactory dysfunction manifested before any classical upper respiratory or pulmonary symptoms in $11.8 \%$ of cases [3]. While $18.2 \%$ of patients denied rhinorrhea symptoms, nearly $80 \%$ of these patients reported reduced olfaction or complete anosmia [3]. A cross-sectional study that included 59 patients with severe COVID-19 hospitalized in Italy found $33.9 \%$ reported anosmia or ageusia [24]. Loss of smell was threefold higher in subjects who tested positive for SARS-CoV-2 (59\%) than in subjects who tested negative (18\%) in a population-based study in the UK [25], and ten-fold higher among ambulatory clinic patients in the USA who tested positive for COVID-19 [26]. The etiology of this phenomenon, and whether it is limited to injury or inflammation in epithelial tissue or represents a possible route of retrograde axonal transport to the CNS is an area of investigation. For example, yet-to-be peerreviewed reports of bulk sequencing gene expression studies have suggested that, as with the respiratory epithelium, the human olfactory epithelium expresses both ACE2 and TMPRSS2, key genes thought to be involved in SARS-CoV-2 infection [27, 28]. However, by using single cell RNA-sequencing analysis and immunostaining techniques, expression of ACE2 was isolated, not to olfactory sensory neurons or neurons of the olfactory bulb, but to the non-neuronal support cells of the olfactory epithelium, and sustentacular cells in particular [28]. This suggests that non-neuronal epithelial tissue may be the infectious target.

A clinical report describes a SARS-CoV-2 patient with mild respiratory symptoms and acute anosmia in which bilateral hyperintensity of the olfactory bulbs and of the right gyrus rectus on FLAIR sequence was seen on 
an MRI performed on day 4 of symptoms [29]. Followup imaging 28 days later showed resolution of cortical hyperintensities with slight reduction in thickness of the olfactory bulbs, though clinically the patient had recovered. Notably, two other clinically similar patients had MRI with FLAIR performed on days of illness 12 and 25 that were completely unremarkable. This case, therefore, represents an intriguing and unique report-possibly an in vivo snapshot of viral involvement in an area of the brain associated with olfaction, and it points to what may be one pathway of viral infection from olfactory mucosa to the brain.

Recent studies have shed light on vascular-thrombotic complications associated with COVID-19 infection [1, 30, 31]. Coagulation abnormalities are common in severe illness and appear to be an important indicator of poor prognosis [31]. Sepsis-induced coagulopathy (SIC) has been described in $21.6 \%$ of patients classified with severe COVID-19 and associated with mortality. Heparin treatment in those with SIC or with a markedly elevated d-dimer was also associated with improved survival [31, 32]. The incidence of arterial or venous thromboembolism has been reported to be between 8 and 31\% in patients hospitalized with COVID-19, despite treatment with prophylactic anticoagulation, including deep venous thromboembolism (VTE), pulmonary embolism, acute ischemic stroke (AIS), and cerebral venous sinus thrombosis [33-35]. One center noted that the rate of VTE in COVID-19 infected patients was more than five times greater than that of comparable historical control groups such as patients admitted with non-COVID ARDS or influenza [36]. The American Society of Hematology has recommended that hospitalized patients with COVID-19 be treated with standard thromboprophylaxis [37], but there remains intense debate about the possible benefit of intensified anticoagulation regimens [38].

AIS has been reported in $2.3-5 \%$ of patients hospitalized with COVID-19 [4, 5, 39], though patient series and case reports of AIS continue to accumulate [40-42]. Three COVID-19 patients with multi-vessel AIS and positive antiphospholipid antibodies are described in a recent case series. A 69-year-old patient with no significant past medical history was found to have multiple bilateral cerebral infarcts and bilateral jugular venous thrombi. In the same series, another 69-year-old patient developed ischemia in both lower limbs and two digits of his left hand and had bilateral cerebral infarcts in multiple vascular territories as revealed by $\mathrm{CT}$ imaging [40]. In these patients, anti-cardiolipin and anti-B2-glycoprotein antibodies were positive and lupus anticoagulant (LAC) was negative. In a prospective French series of COVID-19 patients, anti-cardiolipin antibodies were found in $10 \%$ and LAC in $45 \%$ of a hospitalized cohort
[43]. A retrospective study of 221 hospitalized COVID19 patients found cerebrovascular disease in a significant minority with $5 \%$ of the patients developing acute ischemic stroke, $0.5 \%$ cerebral venous sinus thrombosis, and $0.5 \%$ cerebral hemorrhage [39]. Patients with cerebrovascular disease had a heightened inflammatory response and abnormal coagulation with elevated C-reactive protein (CRP) and d-dimer levels. In this series, older age was a risk factor (mean age 71.6 years in the group with cerebrovascular disease versus 52.1 years in those without; $p<0.05)$ [39]. However, AIS has also been described in young patients [42] and even as a presenting feature of COVID-19. A case series from New York described five SARS-CoV-2-positive patients under the age of 50 who presented to medical attention with large-vessel strokes. Only one of the patients in this notable series had a previous history of stroke [41].

There is mounting evidence to suggest that the vascular endothelium may be a key organ in COVID-19 infection. Clinically, it has been noted that the most frequent comorbidities of patients hospitalized with SARS-CoV-2 infection are hypertension, diabetes, and cardiovascular disease, which share endothelial dysfunction as a common feature [44]. The endothelium is also a principal regulator of thrombosis and hemostasis, and endothelial cell dysfunction, induced by COVID-19 infection, may be an important driver of coagulopathy and increased thrombotic burden. Endothelial cell activation induced by infection and resultant disruption of the antithrombotic endothelial surface, excess thrombin generation, and early termination of fibrinolysis are possible contributors to the thrombotic state [45]. Because vascular endothelial cells express ACE2 receptors in abundance, in addition to many other of the cell surface receptors used by SARS-CoV-2 for cell entry, direct viral infection of vascular endothelial cells has also been posited [38, 44, 45]. Varga et al. demonstrated endothelial viral invasion by SARS-CoV-2 on pathology specimens affecting blood vessels in the heart, kidneys, lungs, and small intestine [46]. Virus in the endothelium was accompanied by inflammatory cells and evidence of endothelial cell death, suggestive of an endotheliitis, which might explain microcirculatory injury or failure exacerbating critical illness and organ injury. An interesting clinical case report describes a severely ill patient with COVID19, ARDS, acute renal failure, and altered mental status in whom von Willebrand factor, a marker of endothelial stimulation and damage, was massively elevated at $500 \%$ of normal [47]. The Kawasaki-like syndrome that is now described in young patients following COVID-19 infection and associated with a hyper-inflammatory state is further suggestive of a vascular inflammatory potential of SARS-CoV-2 [48, 49]. 
The longer-term complications of COVID-19 infection remain unknown. As the virus proliferates in lung tissue, inducing inflammation and edema, alveolar gas exchange is disrupted, with the potential to cause hypoxia, anaerobic metabolism, and acid accumulation [50]. Acidosis risks increasing cerebral vasodilation and promoting cerebral edema [50]. Some concern may be raised by autopsy findings of patients infected with other coronaviruses. Autopsies of 8 confirmed SARS-CoV cases in China revealed cerebral edema and marked neuronal injury [51]. Recently, brain autopsies of 18 patients who tested positive for SARS-CoV-2 revealed hypoxic changes in the cerebellum and cerebrum, with neuronal loss in the cerebral cortex, hippocampus, and cerebellar Purkinje cell layer [52]. These studies suggest that CNS injury secondary to severe pulmonary dysfunction may occur. The degree and extent of CNS injury in earlier phases of the disease process, and to what extent this may be clinically relevant to SARS-CoV-2, are still unclear. The clinical observations that have been reported in COVID-19 shed light on the many potential adverse effects of SARS$\mathrm{CoV}-2$ infection on the nervous system and, in particular, how any specific effects of the virus might overlay on commonly observed consequences of critical illness such as critical illness encephalopathy, critical illness neuropathy, and critical illness myopathy. Subsequent studies must address both the short and important longterm neurological consequences of COVID-19 infection and how we can best mitigate disability and avoid morbidities.

\section{Potential Mechanisms of SARS-CoV-2 Mediated Neurological Injury}

The known pathophysiology of SARS-CoV-2 and the other Human Coronaviruses offer clues regarding possible mechanisms of neurological damage. SARS-CoV-2 has now been shown to be capable of invading the CNS, as have other Human Coronaviruses $(\mathrm{HCoV})$, the viral group of which SARS-CoV-2 is a member. SARS-CoV-2 invasion is thought to require both a cell surface receptor for the viral spike (S) protein to bind to as well as priming of the $S$ protein by cell proteases. More specifically, SARS-CoV-2 utilizes ACE2 as its entry receptor and TMPRSS2 cell protease for S protein priming [53]. Cross human tissue surveys of ACE2 and TMPRSS2 positive cells found co-expression of these proteins in nasal goblet and ciliated epithelial cells as well as oligodendrocytes [54]. ACE2/TMPRSS2 co-expression in oligodendrocytes could be one means of CNS infiltration or proliferation.

Cases of acute encephalitis were reported during the SARS-CoV epidemic with virus detected in patient CSF $[55,56]$. Further insight also comes from pathology studies wherein both viral RNA and infectious virus have been detected in brain tissue. A postmortem study examining four individuals with SARS-CoV-related deaths and four control individuals found SARS-CoV antigen and RNA in the cerebrum of the SARS-CoV infected individuals [57]. Other Human Coronaviruses have previously been found in the brain by autopsy studies: $\mathrm{HCoV}$ strains 229E and OC43 were found in 44 out of 90 brain donors as determined by RT-PCR [58]. Interestingly, the prevalence of OC43 was significantly higher in patients with multiple sclerosis (MS) than in controls. Additionally, another study demonstrated an increase in MCP-1 chemokine mRNA in astrocyte cells lines following $\mathrm{HCoV}-\mathrm{OC} 43$ infection [59]. Elevation in MCP-1 has been linked to increased permeability of the blood-brain barrier [60]. Thus, these results suggest that $\mathrm{HCoV}$ infection may exacerbate a predisposition for MS neuropathology and highlight the possibility that coronavirus infection may interact with preexisting or coexisting neuropathology to yield additive or chronic neurologic complications.

Coronaviruses may invade the CNS by either a transneuronal or hematogenous route. One unique feature of SARS-CoV-2, early anosmia, may signify early neuroinvasion through the olfactory bulb as retrograde transport of $\mathrm{HCoV}$ from the nasal epithelium to the olfactory nerve and the CNS has been demonstrated in mice models. Three days after intranasal inoculation with $\mathrm{HCoV-OC4,} \mathrm{transgenic} \mathrm{mice} \mathrm{were} \mathrm{found} \mathrm{to} \mathrm{have} \mathrm{cells}$ containing viral-specific antigens in their olfactory bulbs, but not in the perivascular spaces. By 7 days post-inoculation, there was propagation of the virus throughout the whole brain, coincident with a fatal clinical encephalitis. Like $\mathrm{HCoV}-\mathrm{OC} 43$, SARS-CoV has also been found in the CNS of mice following experimental nasal inoculation. An approximately eightfold increase in the density of SARS-CoV-positive cells in the CNS was observed over 1-2 weeks after infection, principally clustered in the hippocampus [61]. SARS-CoV has been clinically associated with cases of encephalitis, ischemic changes in neurons, and viral particles, and genome sequences have been detected in the brain upon human autopsy [51]. Though SARS-CoV and SARS-CoV-2 share $82 \%$ of their genomic identity, SARS-CoV-2 has unique genetic characteristics, notably encoding proteins that may affect both viral replication and pathogenicity [62]. The implications and significance of these genetic differences are not yet known.

Coronaviruses may alternatively cross into the CNS through a blood-brain barrier compromised by endothelial injury or endotheliitis, inflammatory mediators, transmigration of macrophages carrying the virus, or direct infection of the endothelial cells themselves [11, $53,54,58]$. Once established in the CNS, SARS-CoV, the virus responsible for Severe Acute Respiratory Syndrome 
(SARS), has been shown to be capable of inducing rapid transneuronal spread and death of infected neurons in transgenic mice models expressing human ACE2 receptors [63]. On the other hand, some mice infected with $\mathrm{HCoV}-\mathrm{OC} 43$, a human coronavirus that causes the common cold, develop an acute encephalitis with neuronal infection, or may survive acute infection and develop chronic encephalitis characterized by behavioral changes and persistence of the OC43 virus in affected neurons [64]. Infection of hippocampal and cortical neural cells with HCOV-OC43 in tissue culture has indicated that cell death may occur by apoptosis of both infected and neighboring, non-infected cells [64]. TNF-a, a known trigger for apoptosis, was found to be released by the infected cells and may have contributed to apoptosis in uninfected cells and in infiltration and activation of microglia, a finding consistent with previous studies [65].

Both SARS-CoV and SARS-CoV-2 enter host cells through ACE2 receptors, but phylogenetic data and atomic-level resolution virus-receptor complex analyses suggest that the novel coronavirus may recognize human ACE2 more efficiently $[66,67]$. In a study that introduced clinical-grade soluble human ACE2 (hrsACE2) and SARS-CoV-2 in engineered human tissue, hrsACE2 was able to effectively scavenge the virus inhibiting its attachment to cells [68]. ACE2, which is expressed at high levels in various tissues including alveolar type- 2 cells, brain endothelial cells, neurons, and glial cells [51, 69, 70], regulates the renin-angiotensin system by opposing angiotensin-converting-enzyme (ACE) signaling through the production of the vasodilator peptide angiotensin $[1-7$, 71].

SARS-CoV has been shown to reduce ACE2 levels in the mouse lung without a detectable alteration in ACE expression [72]. In a study of SARS-CoV transgenic mice that expressed human ACE2 receptors, the transgenic mice showed susceptibility to the virus, more efficient replication of the virus as compared to wild-type mice, more severe pulmonary lesions, detectable viral antigen in the brain, and cerebral vasculitis and hemorrhages [73]. By downregulating ACE2 expression, SARS-CoV-2 may upset the delicate balance of ACE/ACE2 cerebrovascular control which may result in unopposed $\mathrm{ACE}$ signal, excessive vasoconstriction, or disrupted cerebral autoregulation.

Infection with SARS-CoV has previously been shown to be associated with high levels of cytokines, including tumor necrosis factor-alpha (TNF $\alpha$ ), interleukin (IL)- $1 \beta$, IL-6, IL-12, and interferon gamma (INF $)$, a phenomenon known as "cytokine storm" [1, 74, 75], and high levels of these "pro-inflammatory" cytokines have been linked to poor outcomes. SARS-CoV-2 shares such pathogenicity, as COVID-19 severity has now been associated with increased levels of IL-1 $\beta$, IL-2, IL-6, IL-7, IL-8, IL-10, IL-17, INF $\gamma$, INF $\gamma$-inducible protein-10, MCP1, G-CSF, TNF $\alpha$, and macrophage inflammatory protein $1 \alpha[1,76-81]$. Elevated ferritin and IL-6, markers of hyper-inflammation, have already been linked to mortality in COVID-19 [1, 82]. Cytokine storms may contribute to both acute lung injury and neurotoxicity; mice infected with influenza A virus demonstrated significant increases in cytokines IL- 6 , IL- $1 \beta$, and TNF- $\alpha$ with vascular hyperpermeability seen in lungs and also the brain within 6 days of inoculation [83]. The integrity of the blood-brain barrier may be disrupted by cytokine-driven injury and immune-mediated toxicity in the absence of direct viral spread or invasion (Fig. 1). Observations suggest that acute necrotizing encephalopathy (ANE), as an example, may be mediated by cytokine toxicity [84]. Cytokines may also be directly neurotoxic, mediate or even inhibit injury to cells of the CNS either alone or acting in synergy [85]. The ways in which the highly activated cytokine signaling seen in SARS-CoV-2 infection may impact neurologic outcome via alteration of neuroinflammatory pathways are not understood.

\section{Conclusion}

The effects of COVID-19 on the nervous system and neurological outcomes after successful treatment have not been well studied. There is an urgent need for clinical and laboratory research to characterize the relationship between SARS-CoV-2 and neurologic injury. In particular, the broad variety of neurologic complications reported in association with COVID-19, such as ischemic or hemorrhagic stroke, encephalopathy, and seizures, suggests direct effects of viral tropism for the CNS, indirect effects through injury to other organ systems, or sporadic synergy between infectious mechanisms and underlying conditions. Mounting evidence suggests that the novel coronavirus is both vasculotropic and neurotropic. To elucidate these pathogenic pathways, larger and more systematic studies will be required, and relevant animal and tissue models must be developed and refined.

Current data on neuropathology associated with COVID-19 are severely limited. This likely reflects under-reporting of neurologic manifestations in the setting of massive coexisting pulmonary injury and sedation, which makes it difficult if not impossible to conduct thorough neurological clinical examinations, particularly in severe cases where such complications may be more common. Furthermore, even when there may be clinical suspicion of neurological involvement, patients with COVID-19 are maintained under strict isolation precautions, and the ability to obtain neuroimaging is limited, further restricting opportunities to 


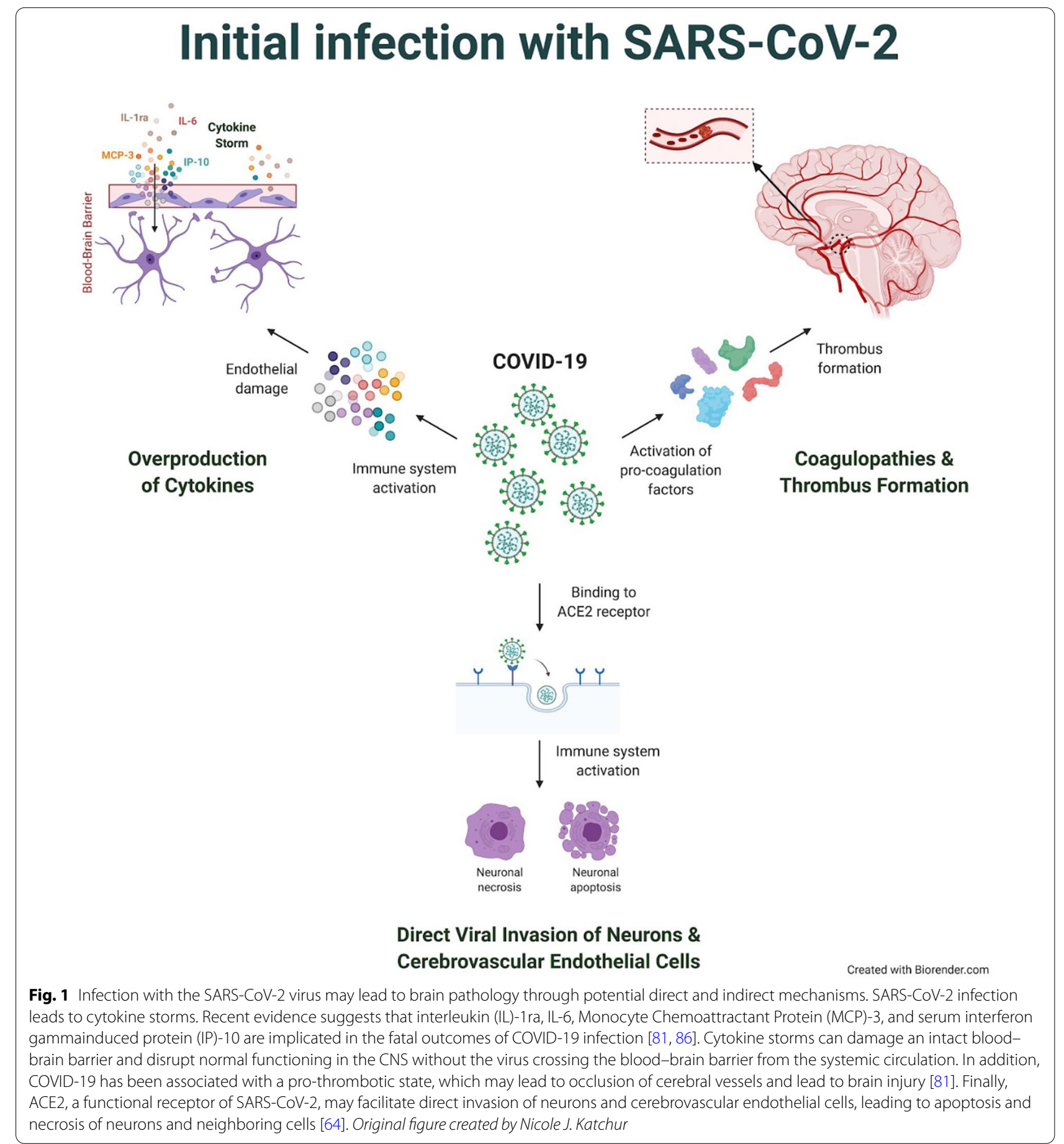

observe and study complications and sequelae. However, efforts must be made to circumvent these challenges in order to better characterize SARS-CoV-2 and its neuropathologic potential. These findings will ultimately help clinicians detect neuropathological signs earlier, attempt therapeutic intervention prior to irreversible injury, and identify compelling neurobiological targets for more optimal treatment and prevention of neurologic injury.

\section{Author details}

${ }^{1}$ Warren Alpert Medical School of Brown University, Providence, RI, USA.

2 Department of Neurosurgery, Warren Alpert Medical School of Brown

University, Providence, RI, USA. ${ }^{3}$ Carney Institute for Brain Science, Brown University, Providence, RI, USA. ${ }^{4}$ Department of Neuroscience, Brown University, 
Providence, RI, USA. ${ }^{5}$ Norman Prince Neurosciences Institute at Lifespan, Providence, RI, USA. ${ }^{6}$ Department of Neurosurgery, Rhode Island Hospital, Providence, RI, USA. ${ }^{7}$ Robert Wood Johnson Medical School, Piscataway, NJ, USA. ${ }^{8}$ Harvard Medical School, Boston, MA, USA. ${ }^{9}$ Division of Pediatric Critical Care, Department of Pediatrics, Massachusetts General Hospital, Boston, USA ${ }^{10}$ Departamento de Neurología, Hospital Clínica Bíblica, San José, Costa Rica. ${ }^{11}$ ILAE-Latin America, International League Against Epilepsy, Flower Mound, USA

\section{Authors' Contribution}

G Aghagoli, B Gallo Marin, and NJ Katchur developed the early ideas of this paper. G Aghagoli, B Gallo Marin, NJ Katchur, WF Asaad, and SA Murphy were the main writers of the initial draft. All authors contributed equally to the editing of the final manuscript.

\section{Source of Support}

This research was supported in part by NIH/NIAID R25AI140490.

\section{Conflict of interest}

The authors declare that they have no conflict of interest.

\section{Ethical Approval}

This manuscript complies with all instructions to authors. The authorship requirements have been met, and the final manuscript was approved by all authors. This manuscript has not been published elsewhere and is not under consideration by another journal.

\section{Publisher's Note}

Springer Nature remains neutral with regard to jurisdictional claims in published maps and institutional affiliations.

Published online: 13 July 2020

\section{References}

1. Huang C, Wang Y, Li X, et al. Clinical features of patients infected with 2019 novel coronavirus in Wuhan, China. Lancet. 2020;395(10223):497506. https://doi.org/10.1016/S0140-6736(20)30183-5.

2. Wang D, Hu B, Hu C, et al. clinical characteristics of 138 hospitalized patients with 2019 novel coronavirus-infected pneumonia in Wuhan, China. JAMA. 2020;323(11):1061-9. https://doi.org/10.1001/ jama.2020.1585.

3. Lechien JR, Chiesa-Estomba CM, De Siati DR, et al. Olfactory and gustatory dysfunctions as a clinical presentation of mild-to-moderate forms of the coronavirus disease (COVID-19): a multicenter European study. Eur Arch Otorhinolaryngol. 2020. https://doi.org/10.1007/s00405-02005965-1.

4. Mao L, Jin H, Wang M, et al. Neurologic manifestations of hospitalized patients with coronavirus disease 2019 in Wuhan, China. JAMA Neurol. 2019. https://doi.org/10.1001/jamaneurol.2020.1127.

5. Helms J, Kremer S, Merdji H, et al. Neurologic features in severe SARSCoV-2 infection. N Engl J Med. 2020. https://doi.org/10.1056/NEJMC 2008597.

6. Kandermirli SG, Dogan L, Sarykaya ZT, et al. Brain MRI findings in patients in the intensive care unit with COVID-19 infection. Radiology. 2020. https://doi.org/10.1148/radiol.2020201697.

7. Duong L, Xu P, Liu A. Meningoencephalitis without respiratory failure in a young female patient with COVID-19 infection in downtown Los Angeles, early april 2020. Behav Immun. 2020. https://doi. org/10.1016/j.bbi.2020.04.024.

8. Poyiadji N, Shahin G, Noujaim D, Stone M, Patel S, Griffith B. COVID19-associated acute hemorrhagic necrotizing encephalopathy: CT and MRI features. Radiology. 2020. https://doi.org/10.1148/radiol.20202 01187.

9. Moriguchi T, Harii N, Goto J, et al. A first case of meningitis/encephalitis associated with SARS-coronavirus-2. Int J Infect Dis. 2020:94:55-8. https:// doi.org/10.1016/j.jijid.2020.03.062.
10. Ye M, Ren Y, LvT. Encephalitis as a clinical manifestation of COVID-19. Brain Behav Immun. 2020. https://doi.org/10.1016/j.bbi.2020.04.017.

11. Paniz-Mondolfi A, Bryce C, Grimes Z, et al. Central nervous system involvement by severe respiratory syndrome coronavirus-2 (SARS-CoV-2). Med Virol. 2020;92(7):699-702. https://doi.org/10.1002/jmv.25915.

12. Pulles VG, Lutgehetmann M, Lindenmeyer MT, et al. Multiorgan and renal tropism of SARS-CoV-2. N Engl J Med. 2020. https://doi.org/10.1056/ NEJMc2011400

13. Mizuguchi M. Acute necrotizing encephalopathy of childhood: a novel form of acute encephalopathy prevalent in Japan and Taiwan. Brain Dev. 1997;19(2):81-92. https://doi.org/10.1016/s0387-7604(96)00063-0.

14. Lee YJ, Hwang SK, Kwon S. Acute necrotizing encephalopathy in children: a long way to go. J Korean Med Sci. 2019. https://doi.org/10.3346/ jkms.2019.34.e143.

15. Wang GF, Li W, Li K. Acute encephalopathy and encephalitis caused by influenza virus infection. Curr Opin Neurol. 2010;23(3):305-11. https://doi. org/10.1097/wco.0b013e328338f6c9.

16. Toovey S. Influenza-associated central nervous system dysfunction: a literature review. Travel Med Infect Dis. 2008;6(3):114-24. https://doi. org/10.1016/j.tmaid.2008.03.003.

17. Kansagra SM, Gallentine WB. Cytokine storm of acute necrotizing encephalopathy. Pediatr Neurol. 2011;45(6):400-2. https://doi.org/10.1016/j. pediatrneurol.2011.09.007.

18. Yoshida T, Tamura T, Nagai Y, et al. MRI gadolinium enhancement precedes neuroradiological findings in acute necrotizing encephalopathy. Brain Dev. 2013;35(10):921-4. https://doi.org/10.1016/j.brain dev.2012.11.011.

19. Zhao H, Shen D, Zhou H, Liu J, Chen S. Guillain-Barré syndrome associated with SARS-CoV-2 infection: causality or coincidence? Lancet Neurol. 2020;10(5):383-4. https://doi.org/10.1016/S1474-4422(20)30109-5.

20. Toscano G, Palmerini F, Ravaglia S, et al. Guillain-Barré Syndrome Associated with SARS-CoV-2. N Engl J Med. 2020. https://doi.org/10.1056/nejmc 2009191.

21. Jacobs BC, Rothbarth PH, van der Meche FG, et al. The spectrum of antecedent infections in Guillain-Barre syndrome: a case-control study. Neurology. 1998;51(4):1110-5. https://doi.org/10.1212/wnl.51.4.1110.

22. Sedaghat Z, Karimi N. Guillain Barre syndrome associated with COVID19 infection: a case report. J Clin Neurosci. 2020;76:233-5. https://doi. org/10.1016/j.jocn.2020.04.062.

23. Gutierrez-Ortiz C, Mendez A, Rodrigo-Rey S, et al. Miller fisher syndrome and polyneuritis cranialis in COVID-19. Neurology. 2020. https://doi. org/10.1212/WNL.0000000000009619.

24. Giacomelli A, Pezzati L, Conti F, et al. Self-reported olfactory and taste disorders in SARS-CoV-2 patients: a cross-sectional study. Clin Infect Dis. 2020. https://doi.org/10.1093/cid/ciaa330.

25. Menni C, Valdes A, Freydin MB, et al. Real-time tracking of self-reported symptoms to predict potential COVID-19. Nat Med. 2020. https://doi. org/10.1038/s41591-020-0916-2.

26. Yan $\mathrm{CH}$, Faraji F, Prajapati DP, Boone CE, DeConde AS. Association of chemosensory dysfunction and Covid-19 in patients presenting with influenza-like symptoms. Int Forum Allergy Rhinol. 2020. https://doi. org/10.1002/alr.22579.

27. Brann D, Tsukahara T, Weinreb C, Logan DW. Non-neural expression of SARS-COV-2 entry genes in the olfactory epithelium suggests mechanisms underlying anosmia in COVID-19 patients. BioRxiv. 2020. https:// doi.org/10.1101/2020.03.25.009084

28. Fodoulian L, Tuberosa J, Rossier D, et al. SARS-CoV-2 receptor and entry genes are expressed by sustentacular cells in the human olfactory neuroepithelium. BioRxiv. 2020. https://doi.org/10.1101/2020.03.35.013268.

29. Politi LS, Salsano E, Grimaldi M. Magnetic resonance imaging alteration of the brain in a patient with coronavirus disease 2019 (COVID-19) and anosmia. JAMA Neurol. 2019. https://doi.org/10.1001/jamaneurol .2020 .2125

30. Chen N, Zhou M, Dong X, et al. Epidemiological and clinical characteristics of 99 cases of 2019 novel coronavirus pneumonia in Wuhan, China: a descriptive study. Lancet. 2020;395(10223):507-13. https://doi. org/10.1016/S0140-6736(20)30211-7.

31. Tang N, Li D, Wang X, Sun Z. Abnormal coagulation parameters are associated with poor prognosis in patients with novel coronavirus pneumonia. J Thromb Haemost. 2020;18(4):844-7. https://doi.org/10.1111/ jth.14768. 
32. Tang N, Bai H, Chen X, Gong J, Li D, Sun Z. Anticoagulant treatment is associated with decreased mortality in severe coronavirus disease 2019 patients with coagulopathy. J Thromb Haemost. 2020;18(5):1094-9. https ://doi.org/10.1111/jth.14817.

33. Lodigiani $C$, lapichino $G$, Carenzo L, et al. Venous and arterial thromboem bolic complications in COVID-19 patients admitted to an academic hospital in Milan, Italy. Thromb Res. 2020;191:9-14. https://doi.org/10.1016/j. thromres.2020.04.024.

34. Cui S, Chen S, Li X, Liu S, Wang F. Prevalence of venous thromboembolism in patients with severe novel coronavirus pneumonia. J Thromb Haemost. 2020. https://doi.org/10.1111/jth.14830.

35. Klok FA, Kruip MJHA, van der Meer NJM, et al. Incidence of thrombotic complications in critically ill ICU patients with COVID-19. Thromb Res. 2020. https://doi.org/10.1016/j.thromres.2020.04.013.

36. Helms J, Tacquard C, Severac F, et al. High risk of thrombosis in patients with severe SARS-CoV-2 infection: a multicenter prospective cohort study. Intensive Care Med. 2020. https://doi.org/10.1007/s00134-02006062-x.

37. Zhou F, Yu T, Du R, et al. Clinical course and risk factors for mortality of adult inpatients with COVID-19 in Wuhan, China: a retrospective cohort study. Lancet. 2020;395(10229):1054-62. https://doi.org/10.1016/S0140 $-6736(20) 30566-3$

38. Connors JM, Levy JH. COVID-19 and its implications for thrombosis and anticoagulation. Blood J. 2020. https://doi.org/10.1182/blood.20200 06000.

39. Li Y, Wang M, Zhou Y, et al. Acute cerebrovascular disease following COVID-19: a single center, retrospective. Obs Study. 2020. https://doi. org/10.2139/ssrn.3550025.

40. Zhang Y, Xiao M, Zhang S, et al. Coagulopathy and antiphospholipid antibodies in patients with Covid-19. N Engl J Med. 2020. https://doi. org/10.1056/nejmc2007575.

41. Oxley TJ, Mocco J, Majidi S, et al. Large-vessel stroke as a presenting feature of Covid-19 in the young. N Engl J Med. 2020. https://doi. org/10.1056/nejmc2009787.

42. González-Pinto T, Luna-Rodríguez A, Moreno-Estébanez A, Agirre-Beitia G, Rodríguez-Antigüedad A, Ruiz-Lopez M. Emergency room neurology in times of COVID-19: malignant ischemic stroke and SARS-COV2 infection Eur J Neurol. 2020. https://doi.org/10.1111/ene.14286.

43. Harzallah I, Debliquis A, Drénou B. Lupus anticoagulant is frequent in patients with Covid-19. J Thromb Haemost. 2020. https://doi. org/10.1111/jth.14867.

44. Santulli G, Morelli MB, Gambardella J. Is endothelial dysfunction the concealed cornerstone of COVID-19? The BMJ. 2020. https://doi.org/10.1136/ bmj.m1091.

45. Marchandot B, Sattler L, Jesel L, et al. COVID-19 related coagulopathy: a distinct entity? J Clin Med. 2020. https://doi.org/10.3390/jcm9061651.

46. Varga Z, Flammer AJ, Steiger P, et al. Endothelial cell infection and endotheliitis in COVID-19. Lancet. 2020;395(10234):1417-8. https://doi. org/10.1016/S0140-6736(20)30937-5.

47. Riphagen S, Gomez X, Gonzalez-Martinez C, Wilkinson N, Theocharis P. Hyperinflammatory shock in children during COVID-19 pandemic Lancet. 2020;395(10237):1607-8. https://doi.org/10.1016/S0140 $-6736(20) 31094-1$

48. Verdoni L, Mazza A, Gervasoni A, et al. An outbreak of severe Kawasakilike disease at the Italian epicentre of the SARS-CoV-2 epidemic: an observational cohort study. Lancet. 2020;395(10239):1771-8. https://doi. org/10.1016/S0140-6736(20)31103-X.

49. Abdennour L, Zeghal C, Dème M, Puybasset L. Interaction cerveau-poumon. Annales Françaises d'Anesthésie et de Réanimation. 2012;31(6):1017. https://doi.org/10.1016/j.annfar.2012.04.013.

50. Gu J, Gong E, Zhang B, et al. Multiple organ infection and the pathogenesis of SARS. J Exp Med. 2005;202(3):415-24. https://doi.org/10.1084/ jem.20050828.

51. Solomon $\mid \mathrm{H}$, Normandin $\mathrm{E}$, Bhattacharyya S, et al. Neuropathological features of COVID-19. N Engl J Med. 2020. https://doi.org/10.1056/NEJMC 2019373.

52. Lau K-K, Yu W-C, Chu C-M, Lau S-T, Sheng B, Yuen K-Y. Possible central nervous system infection by SARS coronavirus. Emerg Infect Dis. 2004;10(2):342-4. https://doi.org/10.3201/eid1002.030638.
53. Stewart JN, Mounir S, Talbot PJ. Human coronavirus gene expression in the brains of multiple sclerosis patients. Virology. 1992;191(1):502-5. https ://doi.org/10.1016/0042-6822(92)90220-j.

54. Sardu C, Gambardella J, Morelli MB, Wang X, Marfella R, Santulli G. Is COVID-19 an endothelial disease? Clin Basic Evid. 2020. https://doi. org/10.20944/preprints202004.0204.v1.

55. Hung ECW, Chim SSC, Chan PKS, et al. Detection of SARS coronavirus RNA in the cerebrospinal fluid of a patient with severe acute respiratory syndrome. Clin Chem. 2003;49(12):2108-9. https://doi.org/10.1373/clinc hem.2003.025437.

56. Ding $Y, H e ~ L$, Zhang Q, et al. Organ distribution of severe acute respiratory syndrome (SARS) associated coronavirus (SARS-CoV) in SARS patients: implications for pathogenesis and virus transmission pathways. J Pathol. 2004;203(2):622-30. https://doi.org/10.1002/path.1560.

57. Arbour N, Day R, Newcombe J, Talbot PJ. Neuroinvasion by human respiratory coronaviruses. J Virol. 2000;74(19):8913-21. https://doi.org/10.1128/ jvi.74.19.8913-8921.2000.

58. Edwards JA, Denis F, Talbot PJ. Activation of glial cells by human coronavirus OC43 infection. J Neuroimmunol. 2000;108(1-2):73-81. https://doi. org/10.1016/s0165-5728(00)00266-6.

59. Stamatovic SM, Shakui P, Keep RF, et al. Monocyte chemoattractant protein-1 regulation of blood-brain barrier permeability. J Cereb Blood Flow Metab. 2005;25(5):593-606. https://doi.org/10.1038/sj.jcbfm.9600055.

60. Glass WG, Subbarao K, Murphy B, Murphy PM. Mechanisms of host defense following severe acute respiratory syndrome-coronavirus (SARSCoV) pulmonary infection of mice. J Immunol. 2004;173(6):4030-9. https ://doi.org/10.4049/jimmunol.173.6.4030.

61. Chan JF, Kok KH, Zhu Z, et al. Genomic characterization of the 2019 novel human-pathogenic coronavirus isolated from a patient with atypical pneumonia after visiting Wuhan. Emerg Microbes Infect. 2020;9(1):22136. https://doi.org/10.1080/22221751.2020.1719902.

62. Murray RS, Brown B, Brian D, Cabirac GF. Detection of coronavirus RNA and antigen in multiple sclerosis brain. Ann Neurol. 1992;31(5):525-33. https://doi.org/10.1002/ana.410310511.

63. Netland J, Meyerholz DK, Moore S, Cassell M, Perlman S. Severe acute respiratory syndrome coronavirus infection causes neuronal death in the absence of encephalitis in mice transgenic for human ACE2. J Virol. 2008:82(15):7264-75. https://doi.org/10.1128/JVI.00737-08.

64. Jacomy H, Fragoso G, Almazan G, Mushynski WE, Talbot PJ. Human coronavirus OC43 infection induces chronic encephalitis leading to disabilities in BALB/C mice. Virology. 2006;349(2):335-46. https://doi.org/10.1016/j. virol.2006.01.049.

65. Robertson J, Beaulieu J-M, Doroudchi MM, Durham HD, Julien J-P, Mushynski WE. Apoptotic death of neurons exhibiting peripherin aggregates is mediated by the proinflammatory cytokine tumor necrosis factor-a. J Cell Biol. 2001;155(2):217-26. https://doi.org/10.1083/jcb.200107058.

66. Wan Y, Shang J, Graham R, Baric RS, Li F. Receptor recognition by the novel coronavirus from Wuhan: an analysis based on decade-long structural studies of SARS coronavirus. J Virol. 2020. https://doi.org/10.1128/ jvi.00127-20.

67. Xu X, Chen P, Wang J, et al. Evolution of the novel coronavirus from the ongoing Wuhan outbreak and modeling of its spike protein for risk of human transmission. Sci China Life Sci. 2020;63(3):457-60. https://doi. org/10.1007/s11427-020-1637-5.

68. Monteil V, Kwon H, Prado P, et al. Inhibition of SARS-CoV-2 infections in engineered human tissues using clinical-grade soluble human ACE2. Cell. 2020;181(4):905-13. https://doi.org/10.1016/j.cell.2020.04.004.

69. Doobay MF, Talman LS, Obr TD, Tian X, Davisson RL, Lazartigues E. Differential expression of neuronal ACE2 in transgenic mice with overexpression of the brain renin-angiotensin system. Am J Physiol Regul Integr Comp Physiol. 2007;292(1):R373-81. https://doi.org/10.1152/ajpre gu.00292.2006.

70. Hamming I, Timens W, Bulthuis MLC, Lely AT, Navis GJ, van Goor H. Tissue distribution of ACE2 protein, the functional receptor for SARS coronavirus. A first step in understanding SARS pathogenesis. J Pathol. 2004:203(2):631-7. https://doi.org/10.1002/path.1570.

71. de Moraes PL, Kangussu LM, Castro CH, Almeida AP, Santos RAS, Ferreira AJ. Vasodilator effect of angiotensin-(1-7) on vascular coronary bed of rats: role of Mas, ACE and ACE2. Protein Pept Lett. 2017;24(9):869-75. https://doi.org/10.2174/0929866524666170728154459. 
72. Kuba K, Imai Y, Rao S, et al. A crucial role of angiotensin converting enzyme 2 (ACE2) in SARS coronavirus-induced lung injury. Nat Med. 2005;11(8):875-9. https://doi.org/10.1038/nm1267.

73. Yang $X-H$, Deng $W$, Tong $Z$, et al. Mice transgenic for human angiotensinconverting enzyme 2 provide a model for SARS coronavirus infection. Comp Med. 2007;57(5):450-9.

74. Huang $\mathrm{K}-\mathrm{J}$, Su I-J, Theron M, et al. An interferon- $-\gamma$-related cytokine storm in SARS patients. J Med Virol. 2005;75(2):185-94. https://doi.org/10.1002/ jmv.20255.

75. Nicholls JM, Poon LL, Lee KC, et al. Lung pathology of fatal severe acute respiratory syndrome. Lancet. 2003;361(9371):1773-8. https://doi. org/10.1016/s0140-6736(03)13413-7.

76. Mehta P, McAuley DF, Brown M, et al. COVID-19: consider cytokine storm syndromes and immunosuppression. Lancet. 2020;395(10229):1033-4. https://doi.org/10.1016/S0140-6736(20)30628-0.

77. Ruan Q, Yang K, Wang W, Jiang L, Song J. Clinical predictors of mortality due to COVID-19 based on an analysis of data of 150 patients from Wuhan, China. Intensive Care Med. 2020;46(5):846-8. https://doi. org/10.1007/s00134-020-05991-X.

78. Wu C, Chen X, Cai Y, et al. Risk factors associated with acute respiratory distress syndrome and death in patients with coronavirus disease 2019 pneumonia in Wuhan, China. JAMA Intern Med. 2019. https://doi. org/10.1001/jamainternmed.2020.0994.

79. Wu D, Yang XO. TH17 responses in cytokine storm of COVID-19: an emerging target of JAK2 inhibitor Fedratinib. J Microbiol Immunol Infect. 2020. https://doi.org/10.1016/j.jmii.2020.03.005.
80. Zhang $W$, Zhao $Y$, Zhang $F$, et al. The use of anti-inflammatory drugs in the treatment of people with severe coronavirus disease 2019 (COVID-19): the perspectives of clinical immunologists from China. Clin Immunol. 2020;214:108393. https://doi.org/10.1016/j.clim.2020.108393.

81. Ma J, Xia P, Zhou Y, et al. Potential effect of blood purification therapy in reducing cytokine storm as a late complication of critically ill COVID-19. Clin Immunol. 2020;214:108408. https://doi.org/10.1016/j. clim.2020.108408.

82. Pedersen SF, Ho Y-C. SARS-CoV-2: a storm is raging. J Clin Investig. 2020;130(5):2202-5. https://doi.org/10.1172/JC1137647.

83. Wang S, Le TQ, Kurihara N, et al. Influenza virus-cytokine-protease cycle in the pathogenesis of vascular hyperpermeability in severe influenza. J Infect Dis. 2010;202(7):991-1001. https://doi.org/10.1086/656044.

84. Ouattara LA, Barin F, Barthez MA, et al. Novel human reovirus isolated from children with acute necrotizing encephalopathy. Emerg Infect Dis. 2011;17(8):1436-44. https://doi.org/10.3201/eid1708.101528.

85. Allan SM, Rothwell NJ. Cytokines and acute neurodegeneration. Nat Rev Neurosci. 2001;2(10):734-44. https://doi.org/10.1038/35094583.

86. Yang Y, Shen C, Li J, et al. Exuberant elevation of IP-10, MCP-3 and IL-1 ra during SARS-CoV-2 infection is associated with disease severity and fatal outcome. MedRxiv. 2020. https://doi.org/10.1101/2020.03.02.20029975. 